\title{
1 \\ All that Glitters Is Gold!
}

Robert D. Blackledge

Retired, former Senior Chemist, Naval Criminal Investigative Service Regional Forensic Laboratory, San Diego, California

Edwin L. Jones, Jr.

Forensic Scientist III, Ventura County Sheriff's Department Forensic Sciences Laboratory, Ventura, California

We've all heard the saying, "all that glitters is not gold." Although not made of gold, tiny particles of commercial glitter may be "as good as gold" in terms of their potential value as associative evidence in criminal cases.

\subsection{WHAT IS GLITTER?}

Glitter is entirely man-made. It may be tiny pieces of aluminum foil or plastic with a vapor-deposited aluminum layer, or it may consist of multiple layers of plastic with no metal layer at all. In the manufacturing process, before it is cut into individual tiny particles, it is in the form of rolled sheets of foil or plastic. Most often the sheets are cut to make particles that are hexagonal, square, or rectangular since these shapes can fully fill a two-dimensional surface with no waste material produced. Although glitter can be obtained in specialized shapes such as circles, stars, and crescent moons, these particles are usually much larger since it is intended that a viewer can see and recognize these shapes.

Forensic Analysis on the Cutting Edge: New Methods for Trace Evidence Analysis, Edited by Robert D. Blackledge.

Copyright (C) 2007 John Wiley \& Sons, Inc. 
Some cosmetics products are advertised as containing "shimmer." "Shimmer" is not glitter. Shimmer starts off as tiny pieces of mica. Although shimmer particles may fall into a certain size range, their shape is totally irregular and random. In order to increase their sparkle the mica pieces may be coated with titanium dioxide, and iron oxides or other pigments may be added to produce color. Although like glitter, shimmer has potential value as associative evidence, it will not be considered in this chapter.

Glitter has been around for many years, but until fairly recently its cosmetic use was primarily for special costume party events such as Halloween and Mardi Gras. But today glitter can be found in every possible variety of women's cosmetic products, and most are intended for everyday wear rather than just for special occasions. Glitter is even found in a number of different brands of sunscreen lotion. There are also many varieties of removable glitter tattoo transfers, and several brands of glitter gel pens in different colors. Glitter is also used extensively in arts and crafts projects. For this purpose it may be sold loose (no vehicle), in pencil sticks (also used in cosmetics), in glues, and in paints. As we shall see later in the chapter, there have been several cases where glitter that had its origination in children's arts and crafts projects became very important transfer evidence. Glitter is used commercially to add decoration to greeting cards, Christmas balls, and other ornaments, and it is used year round to make decorations on women's items of apparel such as T-shirts and sweatshirts. Glitter is also used to add eye appeal to many solid plastic items. In these cases the glitter is within the transparent plastic rather than just on the surface. Glitter is often used in fishing lures, and companies sell glittercontaining dough as well as gels into which lures may be dipped. One company offers a glitter-containing gel that has a fish-attracting maggot aroma! Yeech! We hope we never have a case involving that as trace evidence!

\subsection{THE IDEAL CONTACT TRACE}

In many ways, glitter may be the ideal contact trace. In her master's thesis, Evidential Value of Glitter Particle Trace Evidence, Klaya Aardahl [1] lists the properties of the ideal trace evidence: "(1) nearly invisible, (2) has a high probability of transfer and retention, (3) is highly individualistic, (4) can quickly be collected, separated, and concentrated, (5) the merest traces are easily characterized, and (6) is able to have computerized database capability." Let's see how well glitter meets these ideal properties. Like some other polymer evidence types such as paint and some fibers, they will survive most environmental insults like a hot car, a putrefying body, exposure to sunlight, and exposure to cleaning products.

\subsubsection{Nearly Invisible}

One glitter manufacturer (Meadowbrook Inventions, Bernardsville, New Jersey, USA) offers glitter in 13 different sizes ranging from 0.002 in. $(50 \mu \mathrm{m})$ 
up to $0.250 \mathrm{in} .(6250 \mu \mathrm{m})$, but $0.004 \mathrm{in} .(100 \mu \mathrm{m})$ and $0.008 \mathrm{in} .(200 \mu \mathrm{m})$ are more typical of glitter used in cosmetic products. Under typical viewing conditions we really don't "see" glitter particles, we just see the light reflected off them. It is like seeing a star at night. Although we see the light that long ago originated from the star (or if it is a planet in the solar system we see our sun's light reflected from it), the area of our field of vision that the star or planet occupies is far, far too small for us to actually see it. Unlike more obvious transfers like blood or lipstick smears, because of their small size a criminal is often not aware that some glitter particles have transferred to his/her skin, clothing, vehicle carpeting, and so on. Not being aware of their presence, a criminal takes no measures to remove them or get rid of the clothing items. In at least one case [2] the suspect was known to have unsuccessfully cleaned out his vehicle after committing an abduction/homicide.

\subsubsection{High Probability of Transfer and Retention}

Absent any unusual surface properties (e.g., cockleburs or resin-covered plant materials), small and lightweight particles are more likely to transfer and stick. For example, the larger gunshot residue particles have poor retention on the hands of a shooter. In a small trial reported by Aardahl [1, 3], glitter originating from selected cosmetic products was found to readily transfer and be retained. This is not surprising. For example, glitter made from several layers of polyethylene terephthalate (PET) might typically be $0.008 \mathrm{in} .(200 \mu \mathrm{m})$ in diameter and $0.002 \mathrm{in} .(50 \mu \mathrm{m})$ thick and have a specific gravity of 1.2 . Indeed, small and light.

\subsubsection{Highly Individualistic}

Glitter is class type evidence. With class evidence the smaller the class into which it can be placed, the greater its value as associative evidence. For example, white cotton fibers are so common that they have no associative evidential value and are ignored by criminalists. Whereas the carpet fibers found on so many victims in the Atlanta child murders case could be traced back to a small mill that had only produced that carpet several years previously for a brief period of time and in limited quantity [4]. Therefore, those carpet fibers had great value as associative evidence. How individualistic are glitter particles? The more ways in which glitter from different sources can be shown to vary, the smaller the subclass into which an individual particle may be placed. The smaller the subclass, the more it has value as associative evidence. So let's count the various ways in which we may be able to categorize an individual glitter particle.

Shape. Is the particle hexagonal, square, or rectangular?

Size. What are its dimensions or its area? Many glitter manufacturers offer as many as 12 different size particles. (Square particles are listed as the length of a side and hexagonal particles are listed as the distance from one apex to its opposite apex.) 
Thickness. What is its thickness? Depending on the number of plastic layers and the chemistry of each layer or if there is an aluminum layer, the thickness of glitter particles from different sources may vary. Looking at just one glitter manufacturer's website (Meadowbrook Inventions), for its various glitters the manufacturer lists the following thicknesses: $15 \mu \mathrm{m}$ (Micronic Jewels), $18 \mu \mathrm{m}$ (Metallic Jewels), $25 \mu \mathrm{m}$ (Alpha Jewels HTMP, Cosmetic Jewels, Polyester Jewels), approximately $28-36 \mu \mathrm{m}$ (various glitters in their Crystalina series), $50 \mu \mathrm{m}$ (Alpha Jewels, Clear Polyester, Polyester Pearl Jewels), $65 \mu \mathrm{m}$ (High Chroma Silver/Mirror Crystalina), $75 \mu \mathrm{m}$ (Phosphorescent Poly Glitter), and $175 \mu \mathrm{m}$ (Plastic Jewels).

Specific Gravity. Again at the Meadowbrook Inventions website, the manufacturer lists the following specific gravities: 1.2 (Clear Polyester, Crystalina 400), 1.25 (Polyester Pearl Jewels), 1.3 (High Chroma Silver/Mirror Crystalina), 1.36 (Crystalina 300, Crystalina 310, 311, Crystalina Colors), 1.4 (Alpha Jewels, Cosmetic Jewels, Micronic Jewels, Plastic Jewels, Polyester Jewels), 2.4 (Alpha Jewels HTMP, Metallic Jewels), and 2.5 (Phosphoresescent Poly Glitter).

Morphology. Although many glitter products have no distinctive surface appearance and appear the same on both sides, some have on one side an added pigment that is distinctive in both color and morphology (Figure 1.1).

Number and Thickness of Layers. As with paint chips, individual glitter particles may be cross-sectioned and the separate layers counted and measured (Figure 1.2).

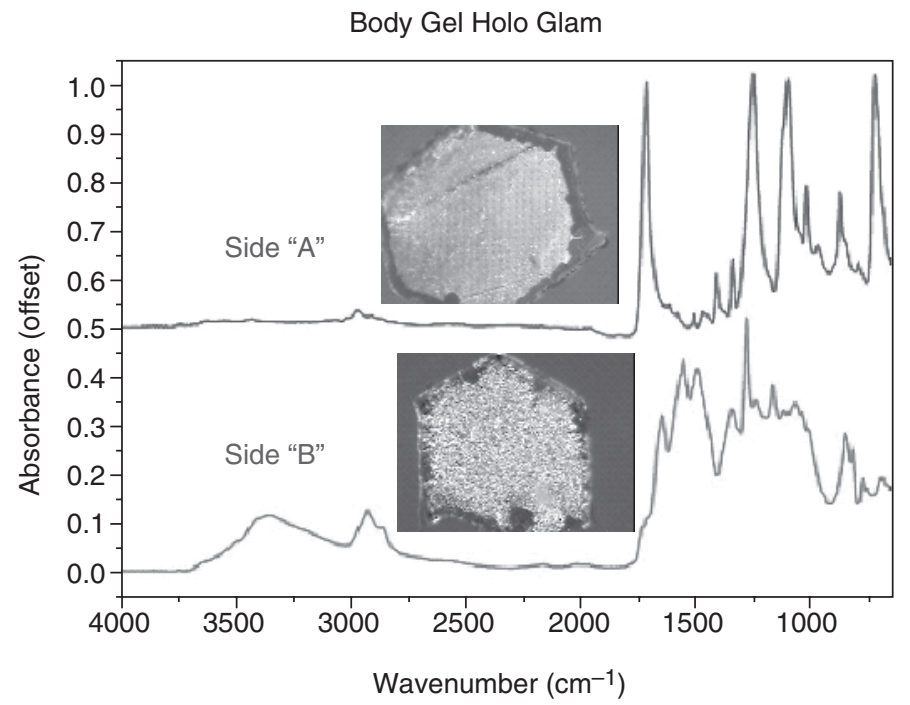

Figure 1.1 (See color insert.) Glitter particle morphology. Two sides of the same particle (700x original magnification) with corresponding ATR FTIR spectra. (From Reference 5.) 


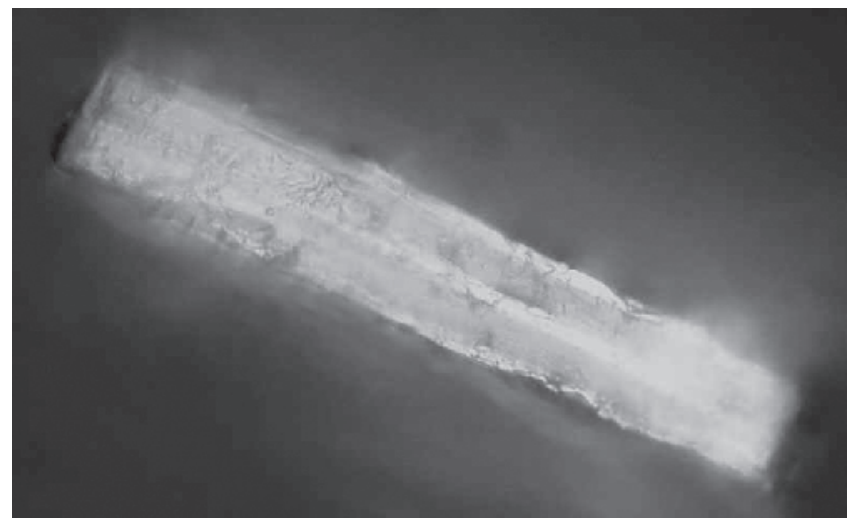

Figure 1.2 A glitter particle in cross section showing five distinct layers. (From Reference 6.)

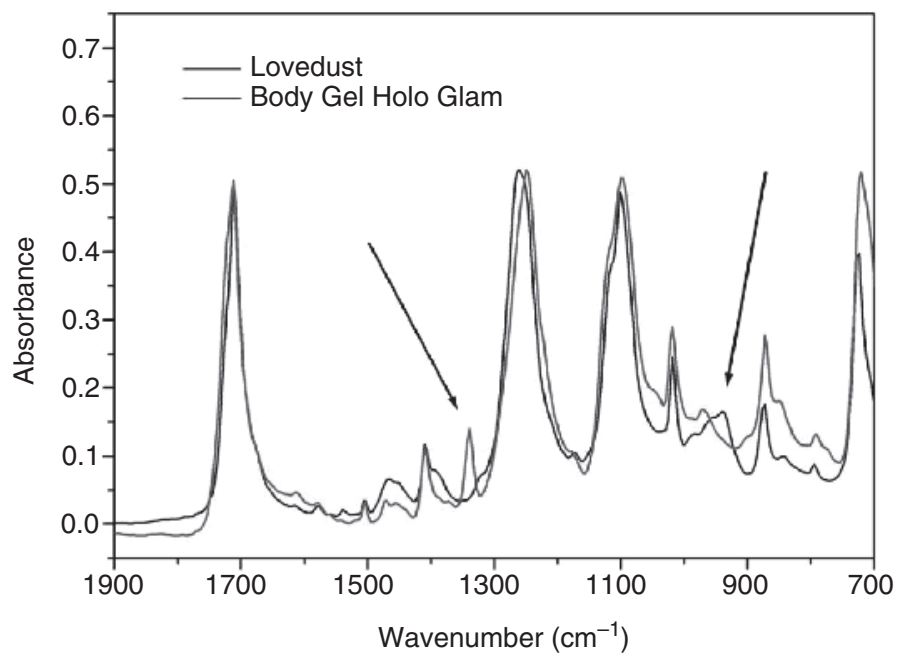

Figure 1.3 Overlay of ATR FTIR spectra from two different glitters shows reproducible differences. (From Reference 5.)

Chemistry of Each Layer. By using methods of infrared spectroscopy the chemical composition of each layer may be determined. The method has the sensitivity to detect even subtle differences in chemistry in particles from different sources (Figure 1.3).

Color. For some of their products manufacturers may offer as many as 48 different colors as well as glitters that fluoresce under ultraviolet light or have holographic properties. Art Institute Glitter, Inc., a company that sells glitter for arts and crafts, offers over 350 different colors in 11 different varieties at 
their website, www.artglitter.com. One variety even consists of tiny pieces of broken glass (Vintage Glass Glitter).

Glitter Manufacturers. If they examine enough properties and have adequate instrumentation, criminalists can usually distinguish paint samples originating from different manufacturers. Although it might not be easy, the same thing should be true of glitter. The more manufacturers there are of glitter, the more variety we would expect. It is not easy to pin down exactly how many manufacturers there are of glitter worldwide. Some companies only make the film and sell it to other companies to be cut into glitter. However, via Internet searches over a dozen manufacturers have been identified in countries including the United States, Germany, India, Pakistan, China, Taiwan, and South Korea. So, how individualistic is glitter? At its website, Meadowbrook Inventions claims over 20,000 varieties, and another large manufacturer, Glitterex Corporation, claims in excess of 10,000 (Table 1.1.).

Cutting Machine Characteristics. There is another way in which glitter might vary. In the manufacture of shoe outsoles, occasionally one of a company's

\section{TABLE 1.1 Glitter Film and/or Particle Manufacturers}

Engelhard Corp., Iselin, NJ, USA [makes film and sells it to glitter cutters] www.englehard.com

Meadowbrook Inventions Inc., Bernardsville, NJ, USA [world's largest glitter manufacturer, with $>20,000$ different products]

www.meadowbrookinventions.com

Glitterex Corp., Cranford, NJ, USA [over 10,000 different glitter prodcts] www.glitterex.com

Spectratek Technologies, Los Angeles, CA, USA

www.spectratek.net

Glitron Products, Pakistan

www.glitron.com

A-Joo Industrial Co. Ltd., Korea

www.ajootex.com

Advance Syntex Pvt. Ltd., India

www.midasglitter.com

Spick Global Films, India [makes film and sells it to glitter cutters]

www.spickglobal.com

Jincolor Co. Ltd., Taiwan

www.jincolor.com

Metlon India Pvt. Ltd., India

www.metlonindia.com

Ho Long Glitters Enterprises Co., Taiwan

www.holongglitters.com.tw

WooSol Industry, Korea www.woosolind.com

Gaoyuan Glitter Materials Co., Ltd., China www.cngaoyuan.com

Masa Glitter, Germany www.masa-glitter.com

RJA Plastics GmbH, Germany www.rja-plastics.com 
several molds for a specific size and right or left outsole will develop a slight defect. As long as this mold defect is barely noticeable, the company will continue to use that mold. Criminalists examining footwear impressions from crime scenes have to be very careful that they don't mistake this mold defect for accidental damage. If it were accidental damage that had occurred during the wearing of the shoe, then this mark could lead the examiner to conclude that no other shoe (than the shoe from the suspect) could have made that impression. But if the mark were due to a mold defect, then every outsole from that particular mold would have that mark. The mark would put the questioned impression into a smaller class, but it would be wrong to conclude that the questioned shoe and only the questioned shoe could have made that impression. In microscopically examining glitter particles from different sources, imperfections from a perfect hexagon or perfect square or rectangle have been noted in some particles in some samples. Although an area that requires more study (visit to glitter manufacturers and collecting samples from specific cutting machines), it is possible that glitter samples that are otherwise alike might be distinguished due to these imperfections. See the photomicrograph in Figure 1.4 for an example of a case where the same imperfection was

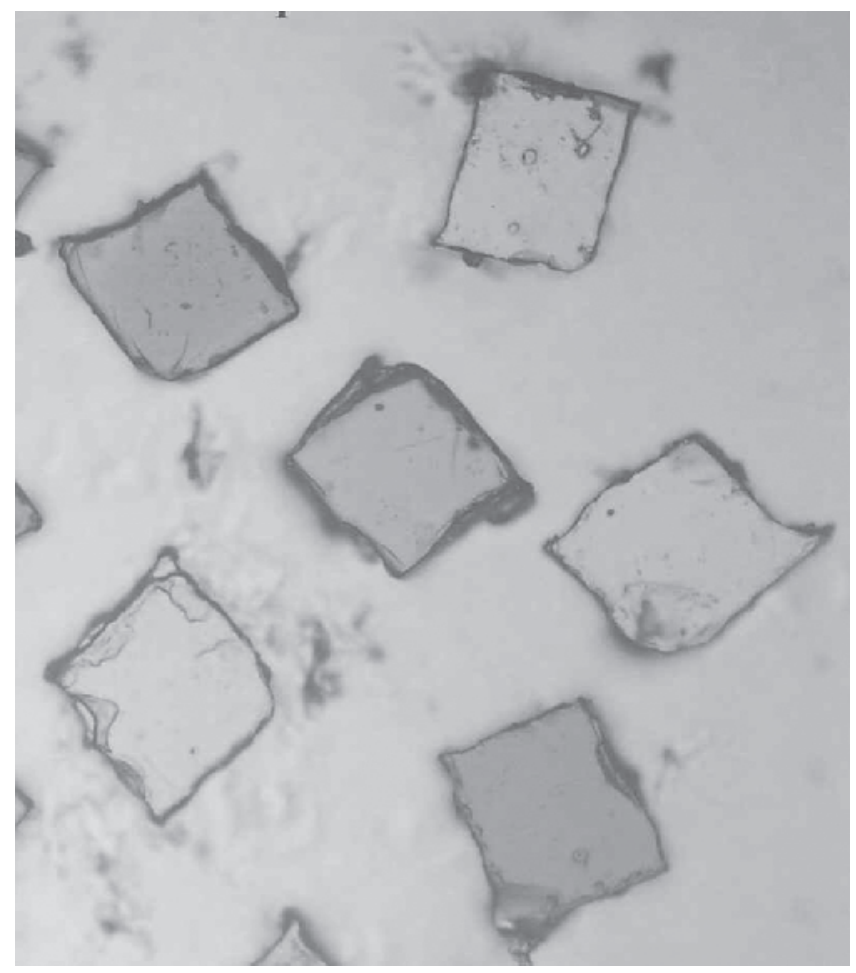

Figure 1.4 (See color insert.) Glitter particles showing cutting machine anomalies (one rounded corner and protrusion on adjacent corner. (From Reference 6.) 
found in both glitter particles associated with the victim and those with the suspect, and therefore increased the likelihood that they had a common origin.

Vehicle. There is potentially at least one more way that glitter particles originating from different sources might be discriminated. When glitter is in cosmetic products it is generally in some vehicle (aerosol hair spray, roll-on, pump spray, lotion, eye liner, lipstick, etc.). Cosmetic products from two different companies might contain identical glitter particles if both companies had purchased the same type of glitter and from the same manufacturer. However, it would be unlikely that the vehicle used by both companies would have identical formulations. If traces of the vehicle still adhered to a recovered glitter particle and if these traces could be extracted and chemically identified, it might be possible to show that these traces did or did not match up with the ingredients in the glitter-containing cosmetic product in the victim's purse. For her master's thesis Chandra Weber [7] used gas chromatography with a mass selective detector and attenuated total reflectance FTIR microscopy in an attempt to recover and characterize vehicle traces from individual glitter particles. These attempts were largely unsuccessful. Either the vehicle was too volatile (hair spray), or it was rapidly absorbed by the skin (lotions). However, with more sensitive instrumentation methods it still might be possible to recover identifiable vehicle traces if the glitter had been in less volatile and less water-soluble cosmetics such as lipsticks and eyeliners. Additionally, glue and paint are frequently used as vehicles in glitter-bearing clothing decorations and in arts and crafts applications.

\subsubsection{Quickly and Easily Collected, Separated, and Concentrated}

Although a criminal may be totally unaware that glitter has transferred to him or his surroundings, glitter particles are easily located and collected when processing crime scenes or examining items of physical evidence. Smaller items may be searched directly using a stereobinocular microscope or a video microscope at low power and illumination with reflected light. Tape lifts can be made over larger items or areas and then the lifts can be examined under low magnification. However, if one is specifically searching for glitter particles it may be more efficient to search under low light conditions and use a flashlight or other bright light source to spot the reflections of individual particles. As a likely individual particle is found it is specifically tape lifted and the specific location where it was found recorded. For this purpose, the authors like to use Post-it ${ }^{\circledR}$ notes. The glue used on Post-it notes is strong enough to lift off the particle, but is weaker than that found on various brands of transparent tape. Because of this the examining criminalist can later more readily pick off the particle for subsequent examinations, and in the process be less likely to damage the particle or have the particle be contaminated with glue from the tape. Another advantage of the Post-it notes is that after collection they can be folded over and all the necessary identifying information written on the 
note prior to it being sealed in an evidence envelope, or the identifying information can be written on the same side as the adhering glitter particle and placed in a small ziplock bag where the evidence can be examined microscopically through the bag.

Location, Location, and Location! Sometimes the location where trace evidence is found is every bit as important as the evidence itself. For example, glitter particles recovered from the pubic hairs of a sexual assault suspect who allegedly forced his victim to perform fellatio might be far more incriminating that those collected from his exterior clothing.

\subsubsection{Easily Characterized}

Although several recovered particles all exhibiting the same properties would make for a better argument against accidental origination from the general environment, only one particle is necessary for characterization. Examples of results from various characterization methods will follow.

\subsubsection{Computerized Database Capability}

For associative evidence any data that will provide even a rough estimate of its rarity will assist a jury in evaluating its evidential value. For fibers numerous target studies have been published (see the references in Reference 3). In a target study a type of trace evidence having specific characteristics is preselected (e.g., orange nylon carpet fibers). Then locations (e.g., theater seats) or garments are randomly selected and sampled by making tape lifts. Then the tape lifts are searched microscopically for fibers exhibiting all the preselected characteristics. The results provide at least a rough idea of the frequency of occurrence of that fiber type in the environments selected. This kind of information may assist a jury in assessing the likelihood that the accused may have innocently picked up these traces from the general environment. A limited target glitter study $[1,3]$ was conducted in the San Diego, California area with four different types of glitter particles preselected. This study indicated a low probability for picking up from the general environment a specific type of glitter particle. Although target studies have value, they also have many limitations. Such studies implicitly assume a random distribution of the targeted items, whereas often they are concentrated in limited areas. In the cited target glitter study, from a total of 58 separate tape lifts 23 contained one or more glitter particles, but of a total of 169 particles recovered, 69 or $41 \%$ were recovered from one tape lift of one seat in a movie theater. While attending the 2003 Annual Meeting of the American Academy of Forensic Sciences, it was noticed that a seat in a meeting room was covered with hundreds of glitter particles while no indications of glitter were seen on adjacent seats or on seats in other rows. Upon approaching the hotel's information desk and explaining why we needed some pieces of transparent tape, we were told that the previous week there had been a convention for people who loved to dance to 
salsa music. Many of the female dancers had worn very decorative costumes. Had we sampled a different seat or from a different room or at a different hotel or at a different city or at a different time of year or even a different year (when the popularity of glitter in cosmetic items was either greater or lesser) our chances of recovering any glitter particles could have varied considerably. Some might argue that a compilation of the frequency with which a specific item is encountered in actual criminal cases would provide a better estimate of rarity. For many years as the FBI Laboratory has encountered fragments of broken glass in evidence items, it has entered their properties (density, refractive index, color (if any), and relative amounts of selected elements) into a database. With each new submission the laboratory can then determine how many times in the past it has encountered a glass sample with these same properties. This too has its limitations (e.g., a type of rope that had never previously been encountered by the FBI Laboratory might actually be fairly common in the village markets around Guadalajara, Mexico (based on transcripts from the trial for the kidnapping and murder of U.S. Drug Enforcement Agency Special Agent Enrique Camarena, July 1988, Los Angeles, CA)). If sufficient number of layers are present on a paint chip that originated from an automotive vehicle, in some cases it may be possible to identify the vehicle manufacturer (Ford, General Motors, Honda, etc.) and the years in which that particular formulation was in use. Manufacturing data may then tell one how many vehicles with that color and that formulation were produced, and thus provide a general assessment of rarity. Most of the properties enumerated for glitter particles (size, shape, thickness, specific gravity, metal layer? (yes/no), opaque/translucent?, different morphology on one side? (yes/no), number of layers, thickness of each layer, chemistry of each layer, and color) are capable of being entered in digital form into a computer-searchable database. Whether such a database was based on target glitter studies, data from previous glittercontaining cases, or data provided by manufacturers, it would at least provide some general estimate of rarity.

\subsection{CHARACTERIZATION METHODS}

In forensic trace-evidence comparisons the null hypothesis is always "Questioned sample, Q, did not originate from the same source as Known sample, K." The reason for this is that this statement can be proved, while the statement "Questioned sample, Q, originated from the same source as Known sample, K" cannot. (For the first statement, as soon as any test shows Q and $\mathrm{K}$ to be different, we have proved it to be correct. With the second statement, we can prove that it is incorrect (a test shows $\mathrm{Q}$ and $\mathrm{K}$ to be different), but no matter how many tests we run that give the same results for $\mathrm{Q}$ and $\mathrm{K}$ there will still always potentially be one more test (that we have not as yet run) that would show them to be different.) And since the object of our tests is to determine if the evidence shows a possible association between the suspect 
and the victim, if there were any rationale for a possible implicit bias on the part of the criminalist it would have to be in favor of the defendant (as soon as a test shows $\mathrm{Q}$ and $\mathrm{K}$ to be different there is no need to conduct additional tests on that evidence). Therefore, in formulating an analysis scheme criminalists tend to first do those tests that are nondestructive, quick, and easy. And since glitter particles are tiny and could easily be lost, those examinations requiring a minimum of particle manipulations would also have precedence. Last in order in any criminalist's examination scheme would be any tests that would actually destroy all or a part of the sample. So although a method such as pyrolysis gas chromatography/mass spectrometry might have high discrimination value, it would not be selected unless it could be shown that no combination of nondestructive tests were capable of discriminating between two samples that were in fact different.

\subsubsection{Color}

Potentially, color has great value for discriminating between glitter particles originating from different sources. For example, PolyFlake, just one of Glitterex Corporation's ten different glitter products, is offered in 44 different colors. One might think that you could just do a side-by-side microscopic comparison of questioned and known particles (or side-by-side comparison of questioned and known particles acquired and saved under identical lighting conditions on a video microscope system). In some cases this is true, but by no means all. Many glitter products contain no dyes or pigments at all. Their color as perceived by a human observer is based on the properties of the various plastic layers in the glitter flake. Some have color-shifting effects and their apparent color will vary according to the lighting and the angle of observation. Criminalists will also encounter this problem when comparing the colors of paint chips from automotive makes and models having optically variable pigments, and also when comparing tiny pieces of mica (shimmer or pearlescent particles). As we roughed out a draft of this chapter we came to the realization that the determination of color when performing traceevidence comparisons was a rather complex subject and was deserving of its own chapter. See Chapter 14 for an in-depth discussion of this subject.

One problem with color determination as perceived by humans (rather than machines) is that it can be quite subjective. Color perception may be affected by lighting conditions. When samples $\mathrm{Q}$ and $\mathrm{K}$ are on different stages of a comparison microscope, whether using reflected or transmitted light, it is very difficult to get the lighting the same on both stages. When small particles that are colored alike are viewed/compared on different colored backgrounds, even those individuals having normal color vision may perceive them to be different. These problems can be somewhat alleviated by capturing the images of $\mathrm{K}$ and $\mathrm{Q}$ particles on the same stage of a video microscope with the same background and same lighting and magnification. However, for elimination of subjectivity and to enable color measurements to be entered into a searchable 
database, it would be desirable to have an objective, machine-determined measurement of color. In a kidnapping/sexual assault case involving glitter as associative evidence [8], a QD1 1000 Microspectrophotometer (Craic Technologies, Altadena, CA, USA) was used to make color comparisons.

\subsubsection{Morphology}

Although most glitter particles have a similar appearance when viewing either surface, some do not. Some may have an added pigment on one surface, and some may have an aluminized layer with plastic layers over. These characteristic morphologies may be viewed at higher magnifications (700 $\times$ or higher), and the chemistries of the two surfaces may be determined by ATR infrared microscopy (Figure 1.1). One must ensure that what appears to be a surface morphology is not due to traces of vehicle on the surface of the particle or due to contamination. Additionally, some glitter products achieve holographic or color-shifting effects by virtue of (Mike Nofi, Flex Products, Inc.) "an embossed foil with a microstructure (grating), coated by an aluminum layer and finally protected by a colored or non-colored resin." Two examples, one with approximately $0.5 \mu \mathrm{m}$ between grating lines and the other with approximately $1 \mu \mathrm{m}$ between lines, are shown in Figure 1.5. The finding on either or both surfaces of a questioned glitter particle of a grating pattern and the mea-

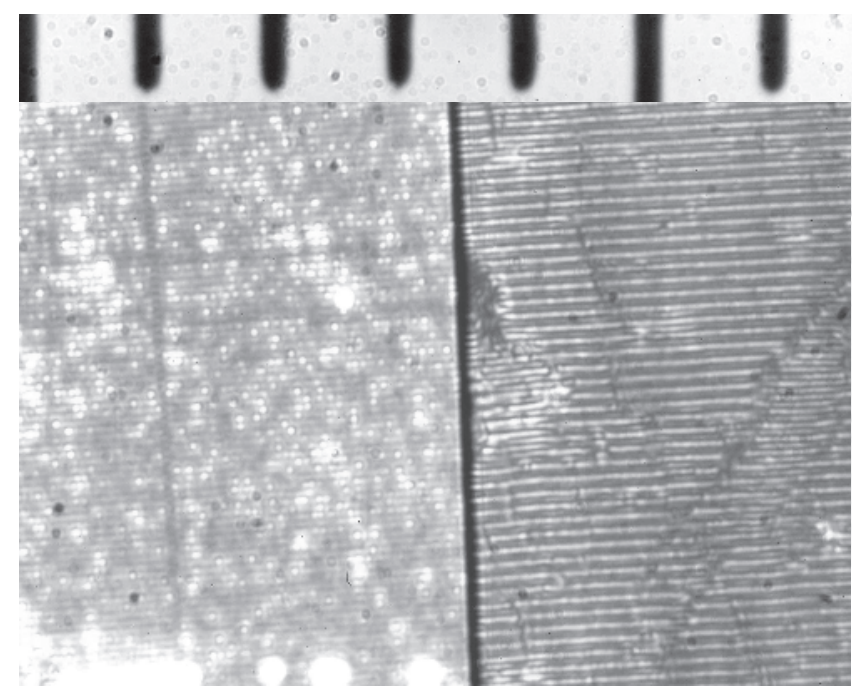

Figure 1.5 Surface of two different glitter particles illustrating an $\sim 0.5 \mu \mathrm{m}$ (left) and $\sim 1.0 \mu \mathrm{m}$ diffraction grating (right). Top is a stage micrometer with lines $10 \mu \mathrm{m}$ apart. Meadowbrook Inventions, Alpha Jewels HTMP, P98000, silver, 0.008in. $\times 0.008$ in. (right), and Alpha Jewels, P9825HX, silver, 0.025 in. hexagonal (left). Conditions: Mounted in Permount ${ }^{T M}$ under a cover glass, 60x dry objective with 0.80 NA and 6.7x photo eyepiece. (Photomicrographs by Edwin Jones, Ventura County (California) Sheriff's Department Forensic Sciences Laboratory.) 
surement of the distance between lines would place this glitter into a much smaller subclass of associative evidence.

\subsubsection{Shape}

Shape is readily determined by examination of glitter particles recovered on tape lifts using reflected light and a stereobinocular microscope or a video microscope at relatively low magnification. Hexagonal shaped particles were most frequently found in the commercial cosmetic products purchased and examined by the authors, as well as those products examined by Aardahl [1] and Kirkowski [5]. Hexagonal particles were also most frequently recovered from the general environment as reported in the target glitter study of Aardahl [1] and Aardahl et al. [3]. Square particles are next in popularity, followed by rectangular. It is rare to find a product that mixes different shapes, but in some cosmetic products containing glitter in a liquid vehicle we have seen mixtures consisting of many tiny glitter particles and much fewer large glitter particles in shapes such as stars or crescent moons. If such a mixture of particles recovered from evidence items associated with a suspect were found to match a product worn by the victim, their associative value would be great. Also, a mixture of particles having different shapes as well as other properties may be encountered if a victim was wearing two or more glitter-containing products. As with fibers, the more different kinds of glitter particles found on the suspect's clothing or in the environment associated with the suspect that match glitter in products worn by the victim, the stronger the association.

\subsubsection{Size}

Kirkowski [5] used a video microscope (Inf-500 ${ }^{\mathrm{TM}}$ CCD Video Microscope (Moritex Corp., Tokyo, Japan)) with a PC that contained video capture software (VisionGauge $^{\mathrm{TM}}$ (VISIONx Inc., Point-Claire, Canada)). Most images of individual particles were captured at either $280 \times$ or $700 \times$. After a simple calibration both the area and the dimensions of an individual particle could be quickly acquired by simply clicking on the particle. Typically in forensic evidence comparisons, one has virtually an unlimited amount of the $\mathrm{K}$ sample and quite a limited amount of the $\mathrm{Q}$ sample. With a system similar to that used by Kirkowski, it would be a simple matter to acquire the average area, average dimensions, and standard deviations of each for the K sample. These properties for the Q particles could be determined and it could quickly be shown whether the $\mathrm{Q}$ particles were included or excluded by size as having a common origin with $\mathrm{K}$.

\subsubsection{Specific Gravity}

The specific gravities of the various glitters (varying from 1.2 to 2.5) listed on the Meadowbrook Inventions website make this property potentially valuable 
for differentiating glitters. The sink float method as outlined in Kirk's [9] book on density and refractive index may be used. This technique involves mixing a liquid with a high specific gravity and a liquid with a low specific gravity together (the liquids must be miscible) along with a solid (glitter particle), which is being tested until the solid neither floats to the top nor sinks to the bottom. When the testing liquid reaches this point an additional solid test subject (glitter particle) can be added. If the additional solid test subject has a higher specific gravity than the first solid, it will sink while the first solid will remain suspended. If the two test subjects are suspended together, then this technique can be refined by using a rise or fall of temperature to alter the specific gravity of the suspending liquid, causing the test subjects to float to the top together and sink to the bottom together. The use of bromoform or tetrabromoethane as the heavy liquid and ethanol or bromobenzene as the lighter liquid should be performed in a chemical fume hood for safety. Waterbased solutions using sodium polytungstate or potassium iodide do not require a chemical fume hood and may be more convenient. Any testing of this technique should be used on the K sample first to make sure that the color in the glitter is color fast and does not dissolve or change in the liquid.

\subsubsection{Thickness}

Thickness of glitter particles can be measured mechanically with a suitable micrometer gauge or optically with a calibrated microscope. A micrometer gauge, which is accurate to the nearest micron, can be used to measure glitter particles. A technique to perform this measurement would involve having the lone glitter particle lying flat on an adhesive tape or Post-it note and zeroing the gauge on the blank area adjacent to the particle, then measuring the particle while it remains on the adhesive. Measurement with a microscope requires a calibrated ocular micrometer. This technique requires the particle to be stood on its edge (with the aid of adhesive or clay) or cross-sectioned.

For those glitter particles that are translucent, the interference fringes present in their infrared spectra can provide an alternative method of thickness determination. The following procedure is taken from Smiths Detection Application Brief AB-060 [10].

Additionally, the optical thickness of glitter particles can be measured using the all-reflecting objective on the IlluminatIR. With a film thickness of 5 to 200 microns, the reflection from the top and bottom surfaces creates measurable interference. This interference pattern is a regular periodic oscillation in the transmittance (or absorbance values) and it is best observed in spectral regions where there are no strong absorption bands as shown in Figure 1.6 for nylon 6,6.

The calculation of the thickness is performed as follows:

$$
\begin{gathered}
t^{\prime}(\mathrm{mm})=N / 2 \times[10 /(W h-W l)] \\
t^{\prime}(\mathrm{mm})=2 / 2 \times(10 / 540)=0.0185 \mathrm{~mm}
\end{gathered}
$$




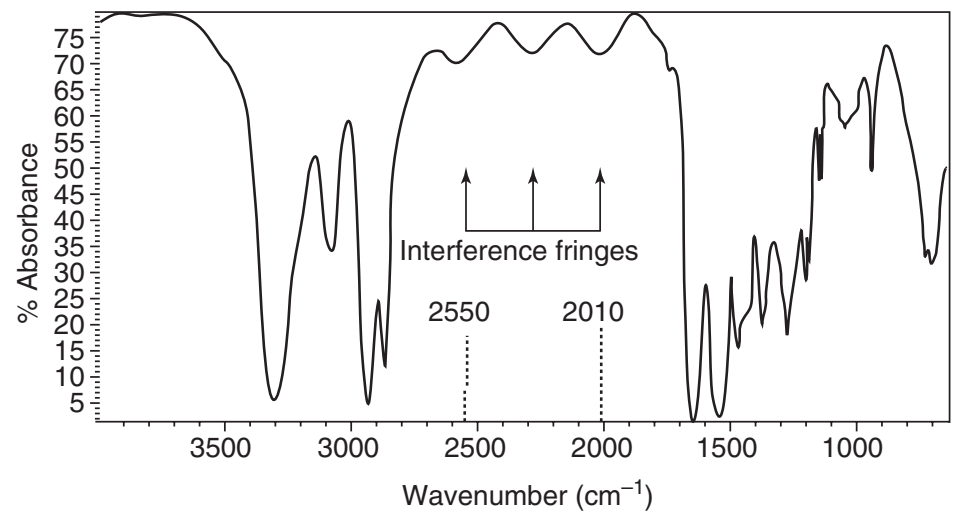

Figure 1.6 IR spectrum of a nylon 6,6 fiber showing a pattern of interference fringes. (From Reference 10.)

$$
\begin{gathered}
t^{\prime}(\mathrm{mm})=\text { optical path length }=n \times t=0.0185 \mathrm{~mm} \\
t=0.0185 / n \text { or } t=0.0185 / 1.5=0.0123 \mathrm{~mm}
\end{gathered}
$$

The optical path $\left(t^{\prime}\right)$ is calculated as shown above. Fringes are counted, starting at zero up to the maximum number $(N)$. To calculate the true film thickness $(t)$ requires knowing the refractive index $(n)$ of the thin film. Since the composition of the plastic glitter particle can be determined from its spectrum, the refractive index can be found in any standard reference.

\subsubsection{Cross Section}

Cross sectioning of glitter can be achieved by hand with the aid of a stereobinocular microscope or with the aid of embedding media and a microtome. To cross-section by hand simply place the glitter flat on a piece of adhesive tape or the adhesive of a Post-it note and cut at $90^{\circ}$ with the aid of a stereo microscope. A fresh razor or scalpel blade and cardboard or other absorbing material (to protect the stage of your microscope from cut marks) may be used. If the objective of the cross sectioning is to obtain a clean layer of material for FTIR analysis, then the angle of the cut needs to be decreased to increase the area of sample available for testing. Encasing the glitter particle in a block of epoxy, Norland Optical Adhesive, or a suitable thermosetting plastic can give better control for separating the layers and producing a very thin section for FTIR analysis.

We have found it surprisingly difficult to obtain cross-sections with no smearing of layers or distortion of the particle. A solution may be to simply view the particle standing on end. Total thickness measurements may be made, the number of separate layers may be counted, and measurements of individual layer thickness may be made, all producing additional levels of 

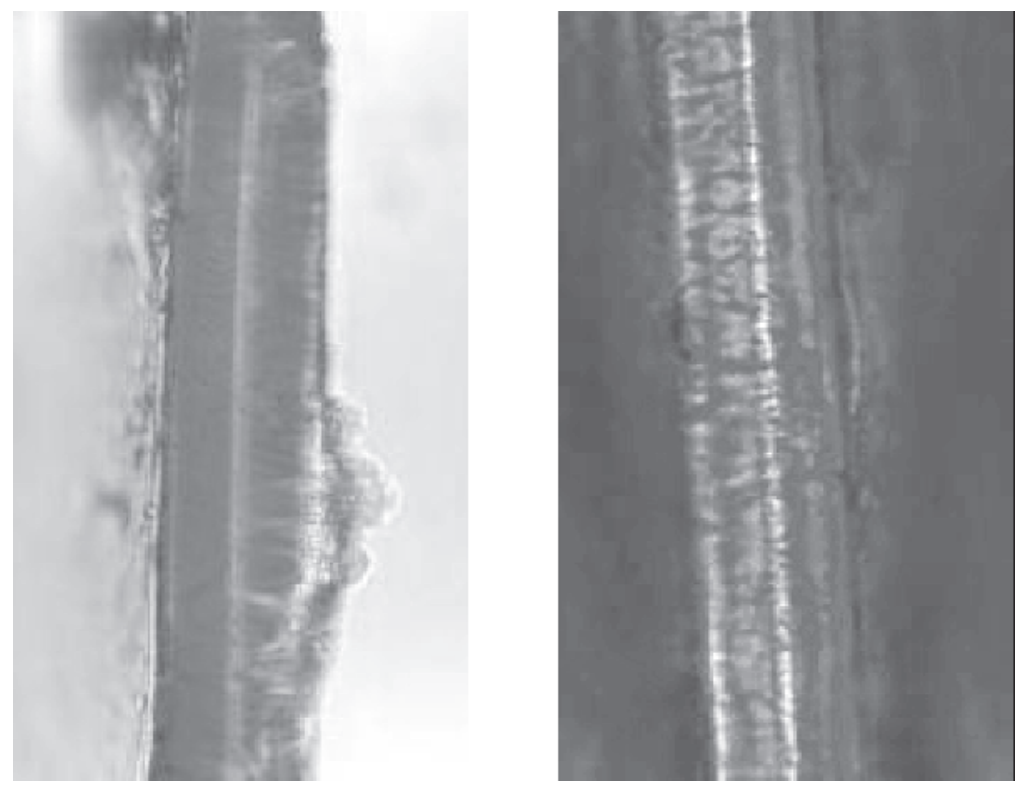

Figure 1.7 (See color insert.) Glitter particle as viewed on edge at 400x. Transmitted light (left) and transmitted light with crossed polars (right). Meadowbrook Inventions, Inc., Crystalina 300 Series, \#326, C3625HX, 0.025in. hexagonal. (Photomicrographs by Michelle Siciliano (Intern) and Gene Lawrence (Criminalist Supervisor), San Diego County Sheriff's Crime Laboratory.)

discrimination. When separate layers consist of chemically different polymers, viewing under crossed polars may heighten appearance differences between layers (Figure 1.7).

\subsubsection{Infrared Spectra}

Kirkowski [5] evaluated several methods of obtaining infrared spectra of individual glitter particles. Even glitter particles that had no opaque aluminum layer and that were translucent were optically too thick to obtain high quality spectra when viewed in transmitted light with an FTIR microscope. This was still true when he attempted to squash a particle in a diamond compression cell and obtain the particle's spectrum in transmission with the cell on the stage of the FTIR microscope. Poor quality spectra were also obtained when a particle was placed on the surface of a gold-coated mirror with the mirror on the stage of the FTIR microscope and the infrared spectrum of the particle's top surface obtained in the reflectance mode.

However, Kirkowski found that high quality infrared spectra of the two surfaces of a particle could be obtained by examining an individual particle using an FTIR microscope having an ATR (attenuated total reflectance) objective. No sample preparation was required other than to ensure that the 


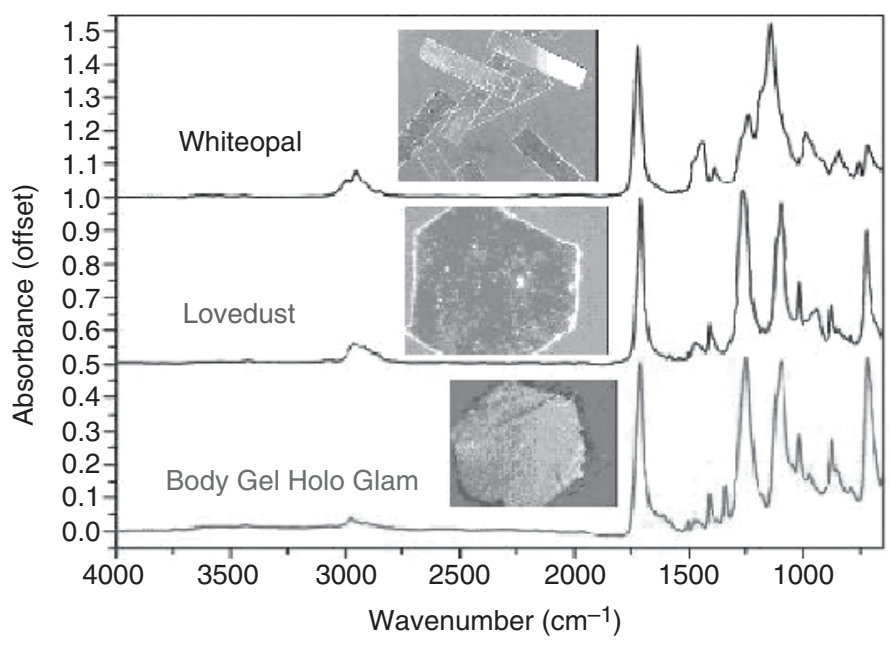

Figure 1.8 (See color insert.) ATR FTIR spectra of individual glitter particles in three different commercial cosmetic products. (From Reference 5.)

particle was clean and that no traces of the vehicle (if the particle had originated from a cosmetic product) or adhesive (if the particle had been recovered using a tape lift) were present. Figure 1.8 shows the FTIR spectra obtained (in absorbance) from individual glitter particles present in three different commercial cosmetic products. The spectra in this figure were obtained with the IlluminatIR ${ }^{\mathrm{TM}}$ Infrared Microspectrometer (Smiths Detection (formerly SensIR Technologies), Danbury, CT, USA) and the ContactIR objective. The IlluminatIR system consists of a high quality optical microscope (Olympus BX51) and the Smiths Detection FTIR accessory. In addition to a standard $10 \times$ optical objective, two infrared objectives are available on the turret. The All Reflecting IR objective is useful for samples such as thin films on metals and obtains the spectra in reflected light. The ContactIR objective employs a diamond to make direct sample contact and obtain spectra using ATR. Because of the design of the ContactIR objective and an included video camera and monitor, the operator can simultaneously view the sample and see when the diamond has made contact and also see that good contact has been made as the sample's infrared spectrum appears on the monitor. Of course, only the infrared spectrum of the outer layer of the side of the glitter particle contacting the diamond is obtained. However, it is a simple matter to turn the particle over and then obtain the spectrum of the other side. To obtain the spectra of any interior layers the particle must be cross-sectioned. As with multilayered paint chips, in order to increase the width of an interior layer it may be necessary to cross-section a particle at an angle rather than at $90^{\circ}$ to the particle's surface. In practice, the glitter particles tend to stick to the diamond objective. After each spectrum is obtained one needs to unscrew the objective, view it at low magnification under a stereobinocular microscope, and pick off the 
particle. A cotton swab moistened with methanol is then used to clean off the diamond. Any methanol traces will quickly evaporate and the diamond objective can be returned to the turret and the system is ready for the next sample.

Figure 1.3 shows an overlay of the infrared spectra obtained for glitter particles from two different commercial products. Even though their spectra are quite similar, there are reproducible differences. So although polyethylene terephthalate (PET) is the most common polymer used in glitter, oftentimes a layer may be a polyester copolymer and FTIR may be able to discriminate between samples. PET is a biaxially oriented polyester film. Mylar ${ }^{\circledR}$ (Dupont) is one of the better known tradenames.

The IlluminatIR system also includes various libraries and search capabilities. Figure 1.9 shows that a search of the middle spectrum in Figure 1.8 (Lovedust) against an ATR library of various polymers (ATR-V01 with 243 entries) gives PET as the closest match with a hit quality of 91.1 out of a possible best of 99.9. Figure 1.10 shows that a search of the top spectrum in Figure 1.8 (Whiteopal) against the same library gives a different polymer, poly(methyl methacrylate), as the closest match with a hit quality of 96.4.

FTIR microscope mapping is a relatively new technique that may be suitable for the examination/comparison of glitter particles in cross section. Let's assume that two or more layers in a glitter particle consist of different poly-

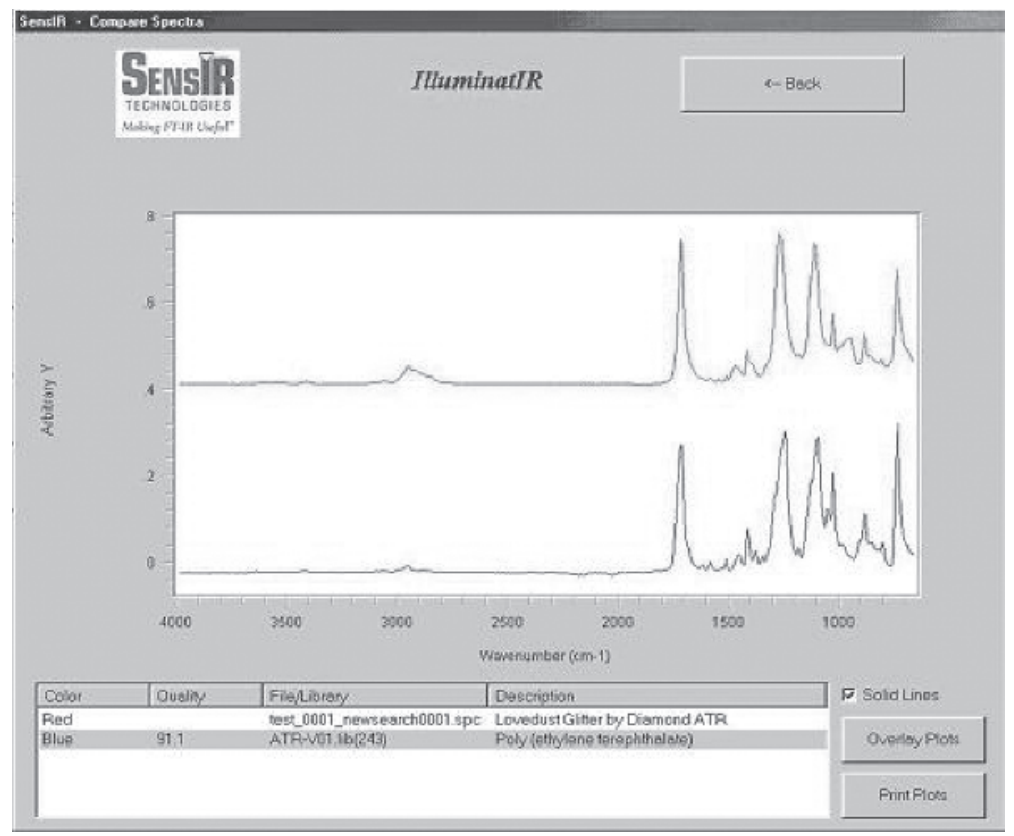

Figure 1.9 Library search of middle spectrum (Lovedust-top) in Figure 1.8. (From Reference 5.) 


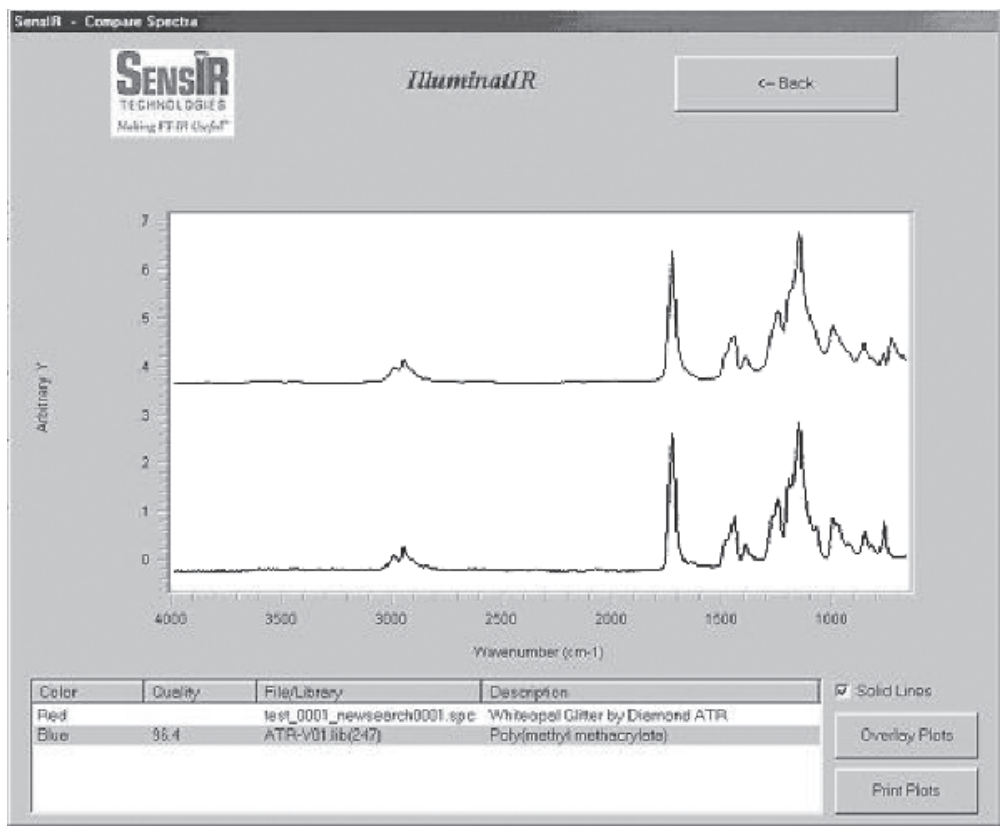

Figure 1.10 Library search of top spectrum (Whiteopal-top) in Figure 1.8. (From Reference 5.)

mers (e.g., PET and poly(methyl methacrylate)). Wavelength bands in the infrared are selected that are specific to one polymer but not found in the other. The entire cross section is scanned for just these two selected wavelengths. For an $x, y$ printout one color is selected for one wavelength (e.g., blue for the wavelength specific to PET) and another color (e.g., red for the wavelength specific to poly(methyl methacrylate)) for the other. The printout would then produce a map of the cross section with all PET layers in blue and all poly(methyl methacrylate) layers in red. However, preliminary attempts at FTIR mapping of glitter particles have been thwarted due to difficulties in obtaining high quality cross sections and because the layers are frequently quite thin.

\subsubsection{Raman Microspectroscopy}

Raman microspectroscopy would appear to be ideally suited for the characterization of the different polymer layers in a glitter particle. Whereas an FTIR microscope with ATR objective can do an excellent job of characterizing the two surfaces of a glitter particle, interior layers can only be characterized subsequent to preparation of a cross section, and even then may present problems if individual layers are quite thin. With a Raman microspectrophotometer the depth of focus can be adjusted so that polymer layers lying below the surface may be located and identified. Following are partial results when four 
different glitter products were examined with a JASCO NRS-3100 Raman system fitted with $532 \mathrm{~nm}$ and $785 \mathrm{~nm}$ lasers and a motorized (mapping) $x-y-z$ stage [11]. Experimental conditions: $100 \mathrm{~mW} 532$ green or $500 \mathrm{~mW} 785 \mathrm{~nm}$ deep red solid-state lasers; $1800 \mathrm{gr} / \mathrm{mm}(532 \mathrm{~nm})$ or $600 \mathrm{gr} / \mathrm{mm}(785 \mathrm{~nm})$ holographic grating; dichroic beamsplitter used with $785 \mathrm{~nm} ; 100 \times$ UMPLFL objective lens; $100 \mathrm{~nm}$ precision automated stage. Crystalina 321 and 421 (both products purchased from Meadowbrook Inventions) were examined and compared. Confocal depth mapping was used. A glitter particle was placed flat on the stage and probed by changing the sample position relative to the laser spot in $1 \mu \mathrm{m}$ increments, from the surface toward the center. This produced an effective sampling volume of approximately $1 \mu \mathrm{m}$ diameter and $2 \mu \mathrm{m}$ thickness $(z)$. The depth resolution was therefore about $2 \mu \mathrm{m}$. Figure 1.11 shows the Crystalina 321 particle.

As shown in Figures 1.12 and 1.13, the Crystalina 421 sample has a clearly defined acrylic surface layer of about 3-4 $\mu \mathrm{m}$ on a polyester core. There was

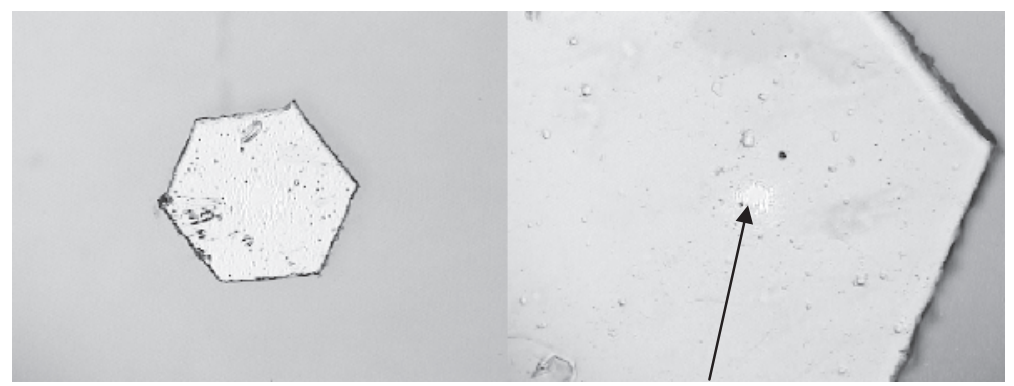

Figure 1.11 Crystalina 321 sample image captured with $5 \times$ and $20 \times$ objective lenses. Position of laser spot is visible in 20x image at right. (From Reference 11.)

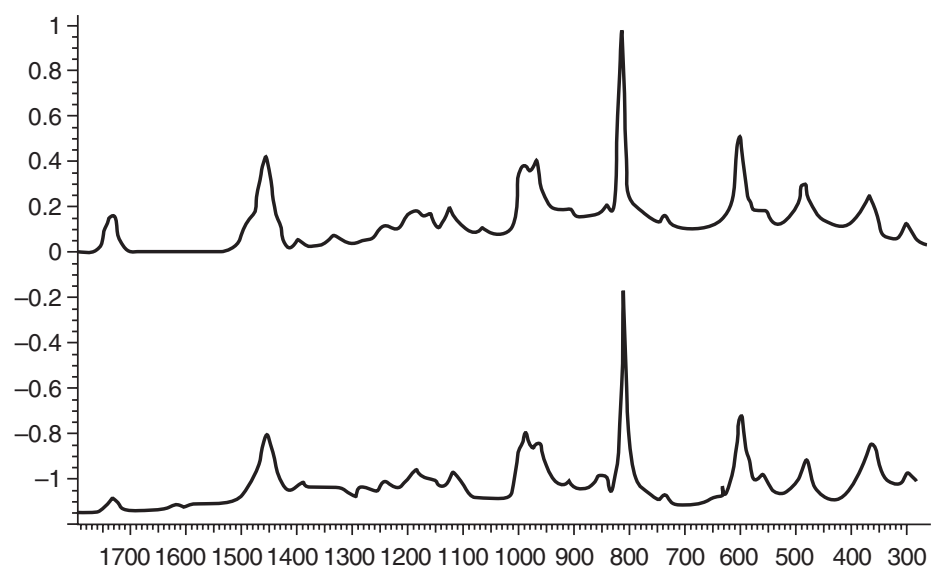

Figure 1.12 Crystalina 421 glitter surface Raman spectrum with $5 \mu$ m depth spectrum subtracted (bottom), compared with database poly(methyl methacrylate) (PMMA) spectrum (top). (From Reference 11.) 


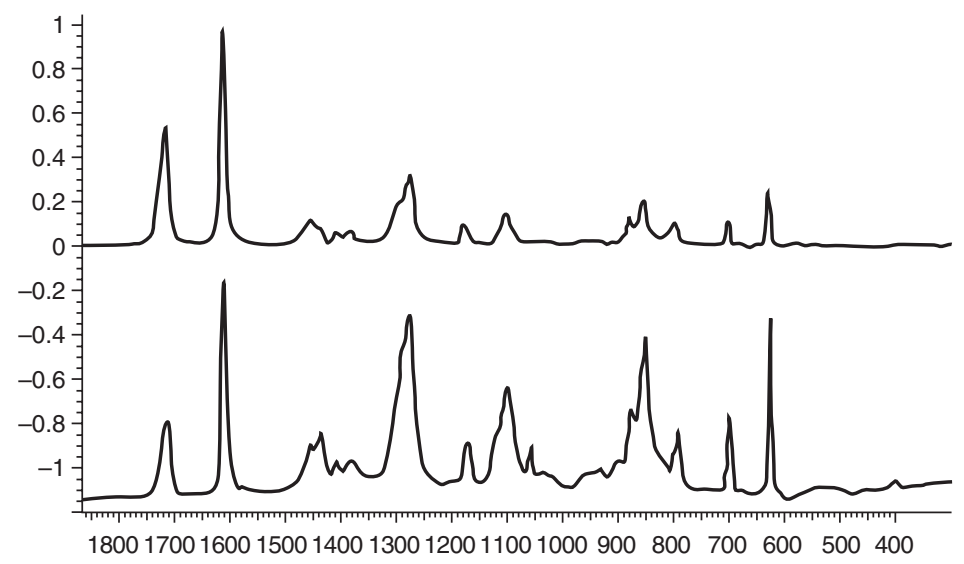

Figure 1.13 Crystalina 421 glitter surface depth map $5 \mu m$ Raman spectrum with surface spectrum subtracted (bottom), compared to database polyester (PET) spectrum (top). (From Reference 11.)

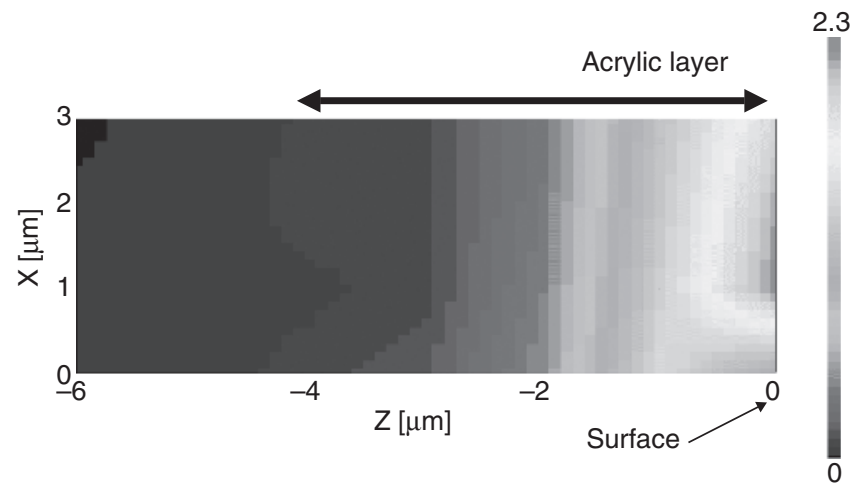

Figure 1.14 (See color insert.) Crystalina 421 peak (2 vs. 1) ratio x-z confocal map. (From Reference 11.)

some inevitable interference by scattering from the adjacent layers because the effective sampling volume $z$ resolution is about $2 \mu \mathrm{m}$, so for positive ID the adjacent layer spectrum was subtracted before running the database searches.

For producing an $x-z$ confocal map (Figure 1.14) raw peak area data were used and a peak found in PMMA but not in PET (peak 2) was ratioed against a peak found only in PET (peak 1).

Although Raman confocal mapping of the data from the Crystalina 421 glitter showed a clearly defined surface PMMA layer over a PET core, with the Crystalina 321 glitter the polymers appear to be mixed (copolymer or 


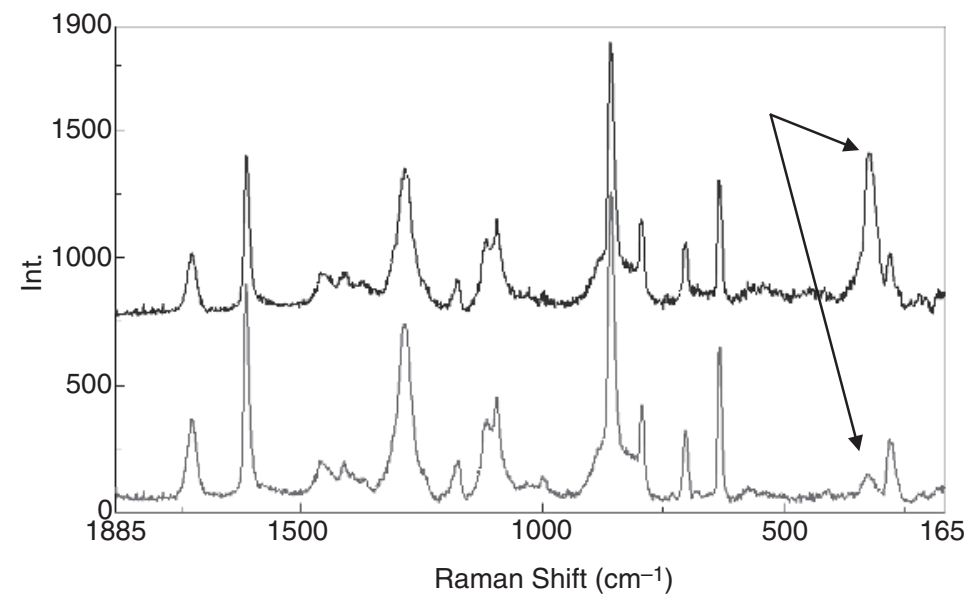

Figure 1.15 Overlaid Raman spectra of glitter from two different commercial products demonstrate that they are similar polyester resins but may differ due to polyester density (marked). (From Reference 11.)

blended). The surface was polyester rich, with a shallow layer slightly richer in the acrylic phase and then becoming more polyester rich at $8-10 \mu \mathrm{m}$ depth. (Full data will be reported elsewhere.)

The other two glitter samples were from different commercial cosmetic products. Each had red hexagonal-shaped glitter particles of the same size, but one contained a single layer of aluminum while the other had two. When laid flat on the stage they only gave weak surface spectra as well as a high background (due to the metallized layers). This was not improved after switching the laser wavelength from $532 \mathrm{~nm}$ to $785 \mathrm{~nm}$. Therefore, these samples were examined edge on rather than face on. Both samples were shown to have only PET layers in addition to the aluminum. However, an overlay of their Raman spectra (Figure 1.15) showed consistent differences between them.

\subsubsection{Scanning Electron Microscopy/Energy Dispersive Spectroscopy}

The scanning electron microscope (SEM) with energy dispersive spectroscopy (EDS) can be used to examine a glitter particle at very high magnification and to analyze its elemental content. The high magnification could be helpful while examining the cross sections. The aluminum layers can be identified with EDS. One of the authors was able to detect the aluminum layer through the $1 \mu \mathrm{m}$ thick color layer on a red glitter particle that only had one layer of aluminum. Flipping this glitter particle to its other side showed that EDS was unable to detect the aluminum through the $25 \mu \mathrm{m}$ of Mylar film and color layer. Even though this glitter had a top side and a bottom side, low power examination with the stereo microscope did not show this. Figure 1.16 shows SEM 


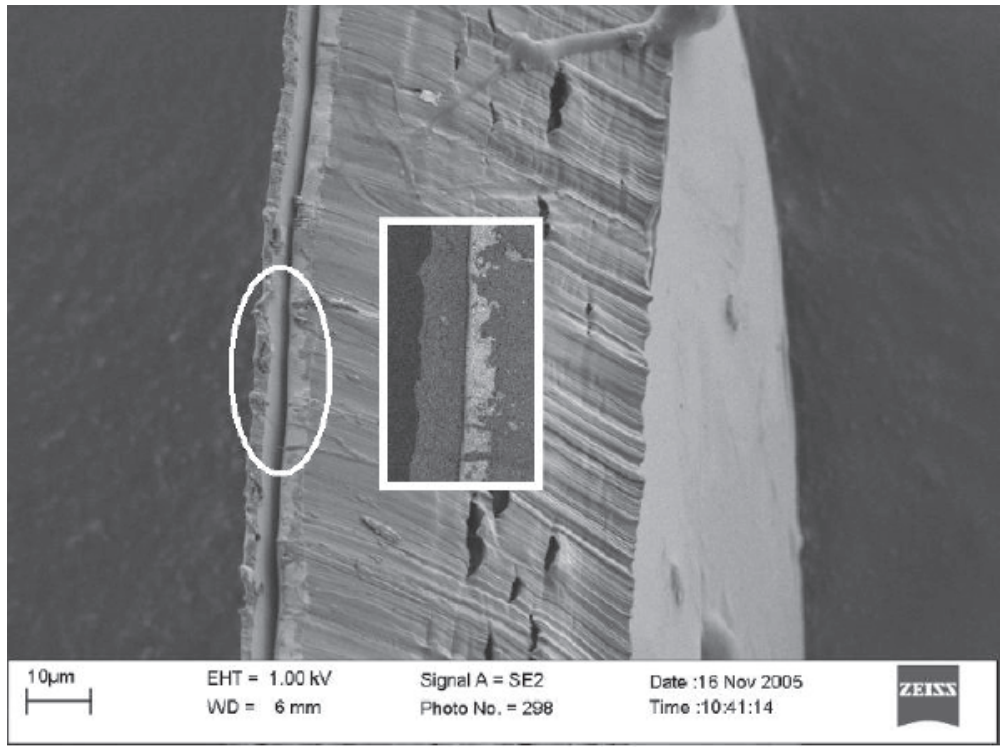

(a)

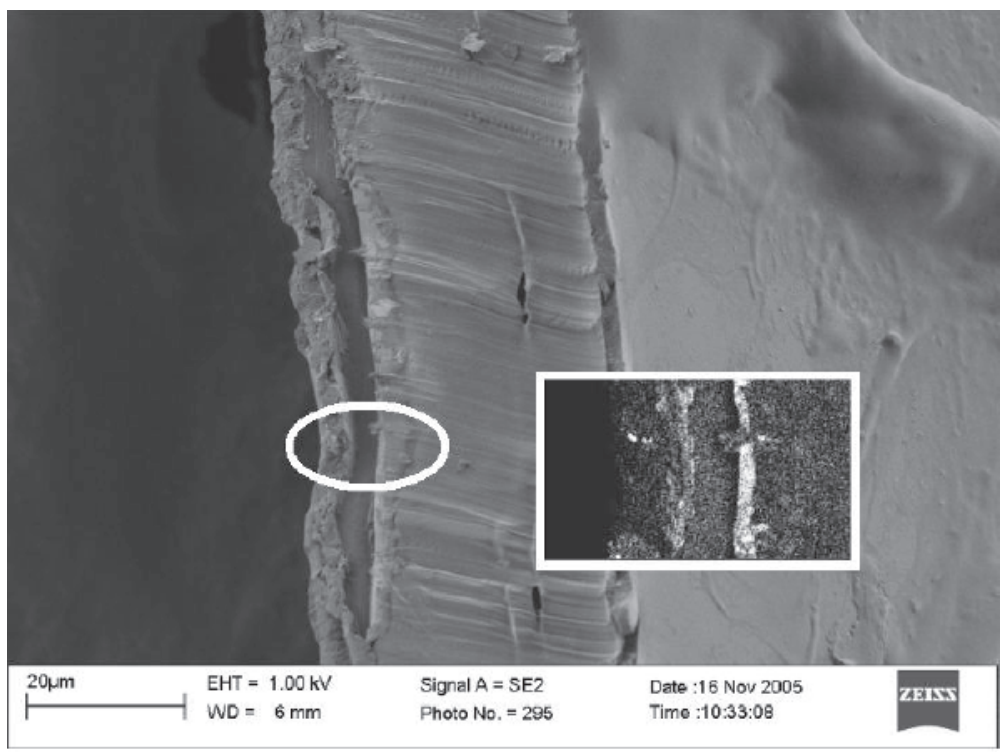

(b)

Figure 1.16 SEM backscatter images of the same two glitter products examined in Figure 1.15. Both have a hexagonal shape and similar dimensions; both are red, and they are about 220-250 $\mu \mathrm{m}$ in diameter. However, the glitter in part (a) has just one thin aluminum layer while the glitter in part (b) has two. The rectangular insets show the backscatter images that correspond to the areas within the ovals. Because of its higher atomic number compared to the carbon, oxygen, and hydrogen in the polymer layer, the single aluminum layer appears brighter against the background in the backscatter image. Although partially obscured by the smearing of the polymer when the glitter particle was cross-sectioned with a scalpel, two separate thin aluminum layers with a polymer layer in between can be seen in the rectangular inset (backscatter image) for the second glitter product. (From Reference 12.) 
[12] images in cross section of the same two very similar (but different) glitter particles whose Raman spectra of their polyester resins are shown in Figure 1.15.

\subsection{GLITTER AS EVIDENCE IN CRIMINAL CASES}

The first paper we could find on glitter as trace evidence was authored by Michael Grieve [13] and published in the Journal of the Forensic Science Society. This was toward the end of the Cold War, and the U.S. Army still had a crime laboratory in Frankfurt, West Germany. Germany has a festive season called Fasching, and as with Mardi Gras in New Orleans the people dress up in costume. The women especially wear costumes and makeup that contain glitter, colored feathers, beads, and so on. In the cases reported by Grieve the victims were German women dressed up for Fasching and they claimed to have been sexually assaulted by male members of the U.S. Armed Forces. Glitter particles were some of the trace evidence found on the clothing of suspects. Grieve not only compared these recovered particles with standards obtained from the victims, he also acquired glitter from other sources. $\mathrm{He}$ found that glitter from different sources exhibited quite a bit of variety and therefore glitter could be valuable associative evidence.

The next case (Alexander v. State) [14] is interesting from several standpoints. First, rather than originating from the victim, the source of the glitter was the suspect's environment. Second, the glitter was from arts and crafts use rather than cosmetics. Third, rather than direct transfer (victim to suspect or suspect to victim), the case involves secondary or even tertiary transfer. In 1987 a high school girl in Fairbanks, Alaska left her home one evening and drove her car back to school so that she could retrieve a book she had left in her locker. She never returned home. Her car was found in the school parking lot with the engine still running. Her body was found late the next day lying on the side of a road on the outskirts of Fairbanks. Glitter was found on her clothing. A suspect was developed and glitter was found in his car. Investigation developed information that the suspect was married and had small children, but was currently estranged from his wife. His wife surrendered several bottles of glitter that had been in the family residence and been used by the children in arts and crafts work. At trial, FBI Special Agent Robert Webb testified as an expert on polymers. He testified "that glitter particles found on the decedent's body and clothing, and the medical examiner's sheets, were identical or consistent with the glitter samples surrendered by the suspect's wife."

The FBI was also involved in another homicide case involving glitter for arts and crafts. In September 1994 during a house burglary a young woman and her five-year-old daughter were murdered. The little girl had been using glitter in an arts and crafts project and in the bedroom where the bodies were found glitter was strewn on the bed and carpeting. An unusual aspect of this 
case is that the suspect was originally arrested, but the court later dismissed the complaint. Then in 1999 (five years later) he was rearrested when glitter was found in his car and the FBI Laboratory determined it to be consistent with glitter found at the scene of the murders. For eight months after the murders the defendant used the car (including using it for transporting his children). The car then sat in his yard inoperable for some time until it was towed to a junkyard. It remained there until the police towed it to their facility for inspection. In a pretrial motion to suppress the glitter as evidence the defense claimed that the defendant's "children played with glitter during that time and that they occasionally played in the vehicle while it sat inoperable in his yard, and that no glitter was found in the vehicle when it was first searched right after the murders in 1994." At the Annual Meeting of the American Academy of Forensic Sciences held in Chicago in February 2003, Dr. Maureen Bradley of the FBI Laboratory presented a poster based on this case, "Glitter: The Analysis and Significance of an Atypical Trace Evidence Examination" [15]. The poster disclosed "a total of ten pieces of glitter of four different colors were recovered from the driver's side carpet of the suspect's car." (Remember what we said earlier about "location, location, and location!" If the glitter had been transferred when his children played in his car, how likely would it be that it would only be deposited on the driver's side carpet?) The abstract for the poster goes on to state: "Each piece of glitter was comparable in size, shape, and color to corresponding glitter from the crime scene. All were approximately $1 \mathrm{~mm}^{2}$ with an aluminum substrate and each had a distinctive notch on one side. The coating on each piece of glitter was analyzed using Attenuated Total Reflectance (ATR) infrared spectroscopy and scanning electron microscopy with energy dispersive X-ray analysis (SEM/ EDXA)." In addition, the FBI obtained 11 different commercially available glitters and compared them with the glitter in the case. All but one of these 11 samples could be distinguished from the case glitter based on physical attributes and/or ATR. SEM/EDXA was then able to distinguish three of the four colors in the case glitters from this sample.

Glitter that was sprinkled onto the victim's head during a 4th of July party was valuable associative evidence in a case in Moorpark, California, where a serial rapist's crimes eventually escalated to abduction and murder [2]. The morning after the abduction, the suspect was observed cleaning out his vehicle for several hours. Weeks latter the vehicle was tape lifted with Helmac lint rollers and 20 glitter particles were recovered (15 of them from the front seat). One month after the abduction, the victim's body was recovered in an advanced state of decomposition. Ten (10) glitter particles were picked out of the victim's hair with a stereo microscope and fine forceps. Despite the one-month exposure to the outdoor elements and the decomposition products exuding from the body, the glitter particles compared favorably with the particles recovered from the suspect's truck and the empty glitter bottle used to sprinkle the glitter onto the victim. Investigation into the source of the glitter revealed that 10,000 bottles of that glitter were produced exclusively for a national retail store. 
Jones tried without success (approximately two months after the crime) to obtain a sample from three of the local retail stores including the store where the original bottle was purchased.

The U.S. Army Criminal Investigation Laboratory (USACIL) in Atlanta, Georgia had a sexual assault case where glitter was found on the underwear of the male suspect as well as on two used condoms left at the crime scene [16].

In Hannibal, Missouri in 2001 a man was accused of the abduction, sexual assault, and murder of a thirteen-year old girl. Glitter particles found on a pair of jeans seized from the back of the suspect's car had the same physical and chemical characteristics as those found on the victim's bedspread. This included an anomaly in the shape of the particles. See the photomicrographs in Figure 1.17 showing glitter particles recovered from the suspect's blue jeans; glitter particles recovered from the victim's bedspread; and glitter particles recovered from the victim's blue jeans that were found on the floor of her bedroom. Although the particles are generally square, one of the corners is rounded and there is a protrusion on an adjacent corner. This anomaly suggests that all of the particles may have been cut on the same machine. Figure 1.18 shows the infrared spectra of individual glitter particles recovered from the three sources. In addition, glitter particles from all three sources were examined in cross section. Particles were also measured in terms of size and thickness $(25-30 \mu \mathrm{m})$. In addition to visual microscopic comparisons, colors of individual particles were also measured with a microspectrophotometer in the visible region [6].

An individual was found guilty of kidnapping and sexual assault in a case in Illinois [8]. This case was interesting in that it involved transfer of particles of glitter from a design on the victim's shirt to the clothing of the suspect. A twelve-year-old girl had been attacked in a wooded area in southern Illinois. She was beaten and her throat was cut, but she bit the attacker, kicked him in the groin, and was able to escape before any sexual act was accomplished. She ran home and her mother rushed her to the hospital and en route contacted law enforcement. Sheriff's department personnel searched the area but were unable to locate a suspect. An Illinois State Police Crime Scene Investigator was called in to do a sketch of the suspect, and this was distributed to the local media. The day after the sketch appeared in the local newspaper, a citizen came forward and said he saw someone matching that description in the city park, not too far from the location of the attack. The sheriff's department searched the woods near the park and discovered a small shack. An occupant matching the description of the suspect came out of the shack with a knife in his hand, but dropped it when he realized he was staring down the barrel of a 45 caliber handgun. Upon arrest and interrogation the suspect provided some details of the incident, including the location of the jacket he had been wearing during the attack. The jacket, his clothing, and the victim's clothing were turned over to the Illinois State Police Crime Laboratory at Carbondale for analysis. The suspect's clothing was examined first. Some blood-like stains were observed on his leather jacket. His jacket and other clothing were taped 

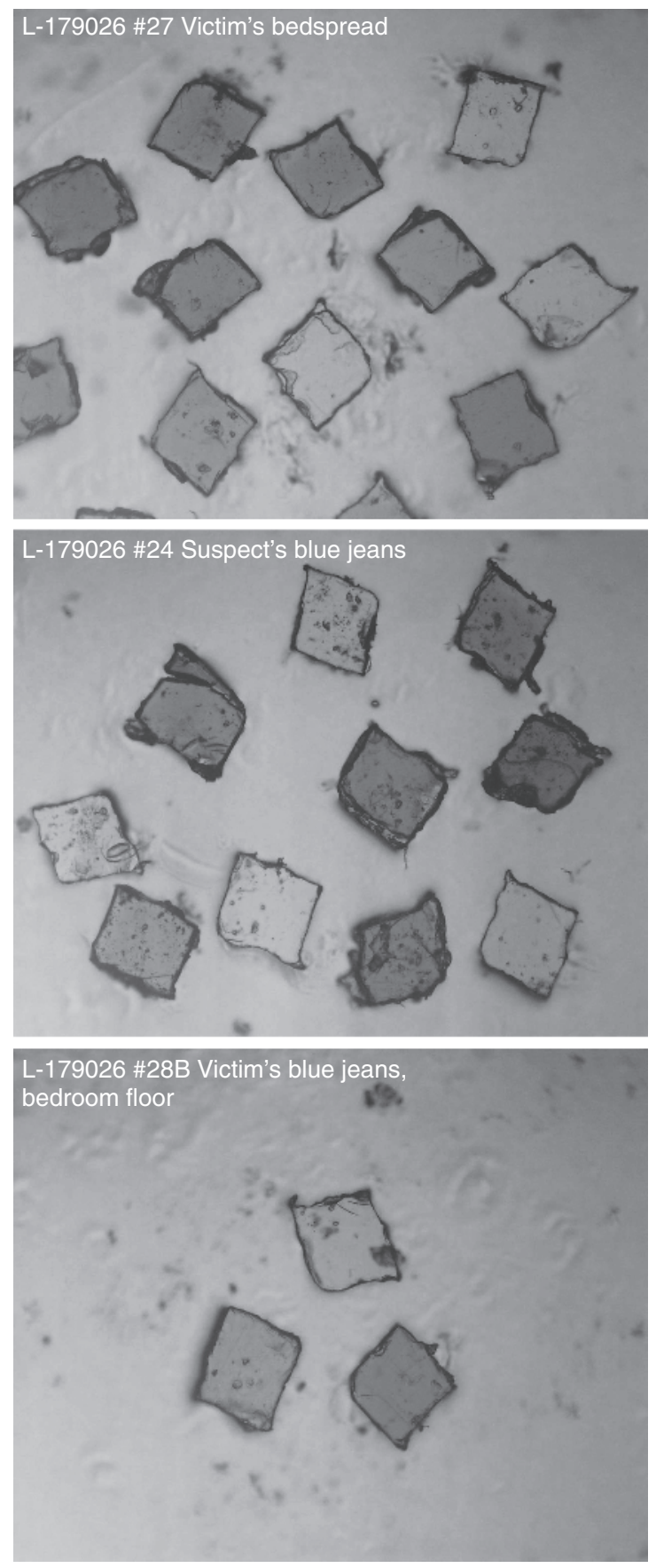

Figure 1.17 (See color insert.) Glitter particles recovered from victim's bedspread (top), suspect's blue jeans (middle), and victim's blue jeans (bottom). (From Reference 6.) 


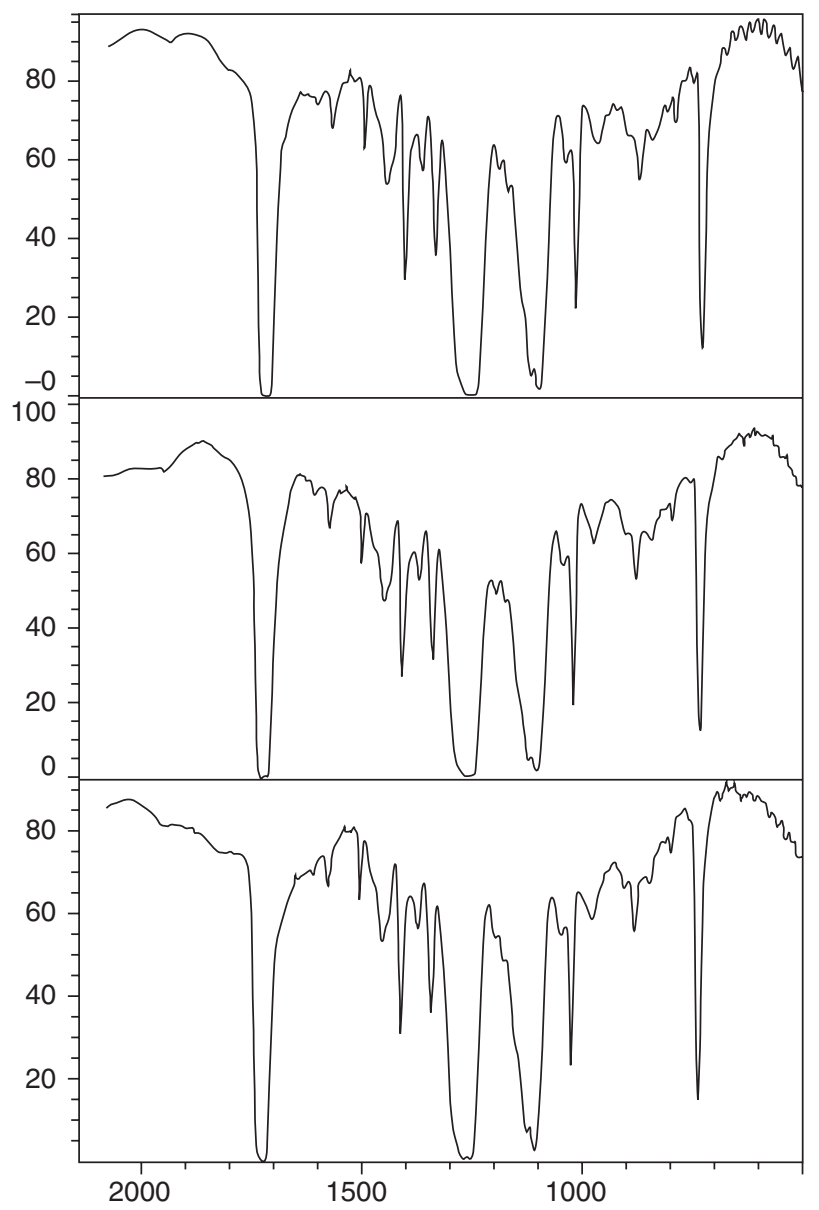

Figure 1.18 Infrared spectrum of glitter particle recovered from victim's bedspread (top); suspect's jeans (middle), and victim's blue jeans (bottom). (From Reference 6.)

with clear book tape to remove trace debris. Microscopic examination showed that the collected trace debris included numerous small silver-appearing particles. Could these be like the glitter from the victim's shirt? Higher magnification showed the particles to be small hexagon-shaped glitter particles. A total of five silver-appearing, hexagon-shaped glitter particles were recovered from the suspect's clothing - three from his jeans, one from his sweatshirt, and one from his jacket. In a different room, the victim's clothing was examined. The jacket and shirt she had been wearing at the time of the assault had both been cut several inches down the front center, apparently by the suspect. The word "WARNING" was written in silver-colored glitter on the top front center of the shirt and the cut extended right through this area (Figure 1.19). Glitter particles from the suspect and glitter from the victim's shirt were examined and compared on a comparison microscope under transmitted and reflected light (Figure 1.20). All of the glitter particles recovered from the suspect 


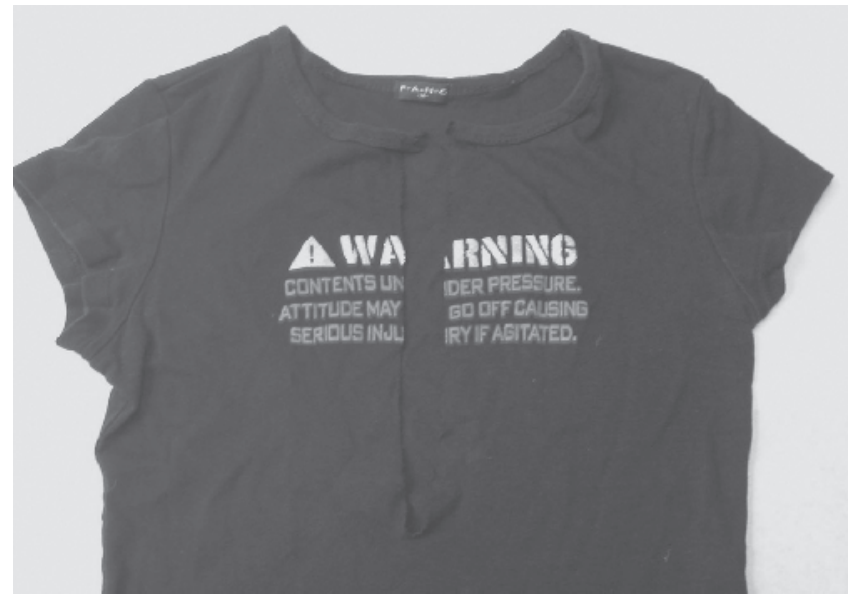

Figure 1.19 Victim's T-shirt with cut through area where the design was created with silverappearing glitter. (From Reference 8.)
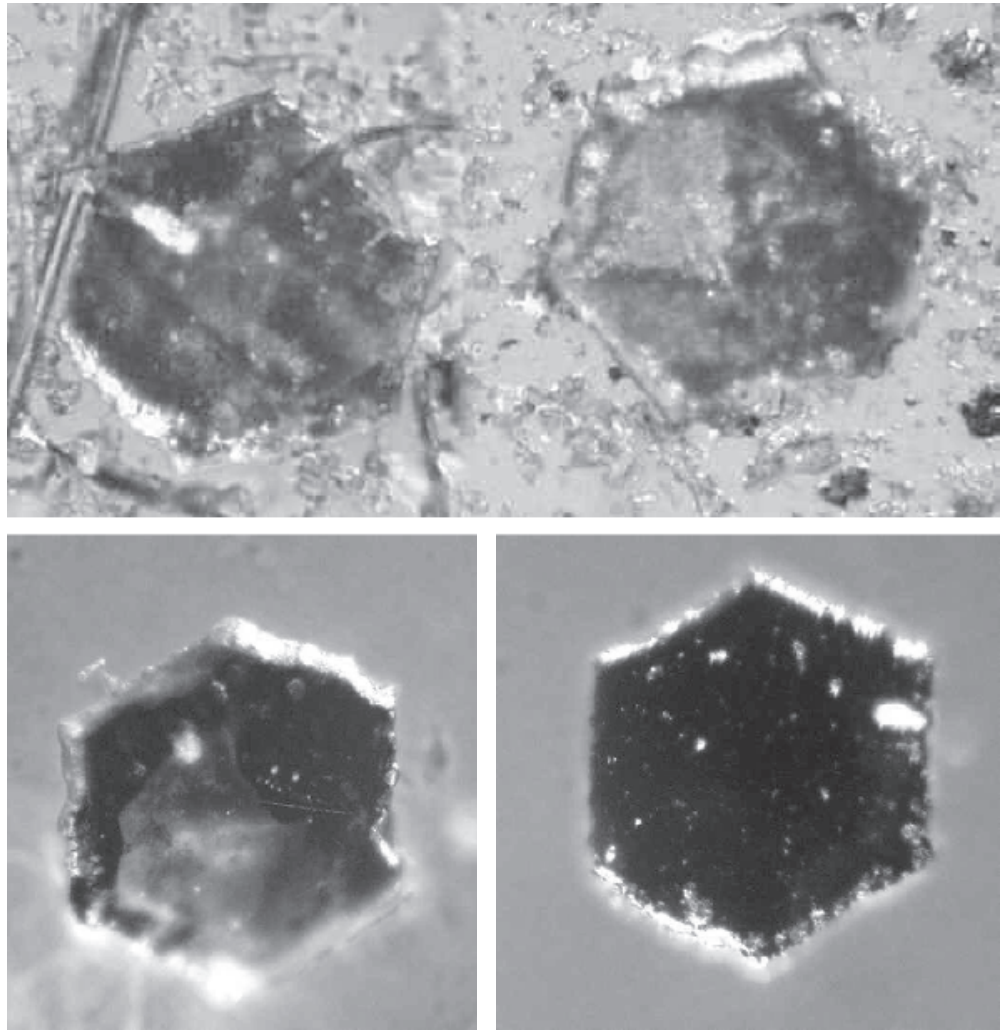

Figure 1.20 Tape lift photomicrograph in reflected light (top) of glitter particle recovered from the suspect's jacket (left) and the victim's shirt (right). Photomicrographs after the glitter particles were picked off the tape and placed on microscope slides (bottom). (From Reference 8.) 
appeared similar to those from the shirt when examined under high magnification. These silver-appearing glitter particles were hexagon shaped and measured about $250 \mu \mathrm{m}$ across. Most had a silver-appearing (actually aluminum) layer on both sides with a clear polymer layer in the middle. The two metal outer layers were removed from one particle from the victim's shirt and then the middle polymer layer was placed in a diamond compression cell and the infrared spectrum of this layer was obtained with an Olympus Continuum FTIR microscope. The same procedure was followed with one glitter particle recovered from the suspect's clothing. With each the polymer was identified as polyethylene terephthalate (PET). Next, the analyst did a color comparison using a CRAIC microspectrophotometer. The metallic layers were thin enough to do the analysis in the transmission mode. Although not showing the same level of sharpness and repeatability as infrared spectra, the analysis did show that the glitter recovered from the suspect's clothing was within the same range of color as the glitter from the victim's shirt. (A reader might well say, "I could tell that by just looking at them under a microscope," but increasingly today the courts, laboratory accreditation bodies like ASCLD-LAB (American Society of Crime Laboratory Directors-Lab), guidelines provided by groups like SWGMAT (Scientific Working Group on Materials; i.e. trace evidence), and defense attorneys clamor for testing methods that are not subjective, do not vary from laboratory to laboratory or between analysts, and can provide data in digital form so that database entries may be made, libraries searched, frequencies of occurrence determined, and error rates calculated.)

At the suspect's trial, the analyst testified that he did not find any differences between the glitter recovered from the suspect's clothing and that from the victim's shirt, and that the victim's shirt could be the source of the glitter that was recovered from the suspect's clothing. A DNA analyst testified that blood recovered from the suspect's jacket matched the DNA profile of the victim. The defendant was found guilty of Predatory Criminal Sexual Assault, Aggravated Kidnapping, and Aggravated Battery of a Child.

Glitter was one of the many types of associative evidence in a bizarre case in Albuquerque, New Mexico [17]. This case has already been the subject of several television programs. Although the victim's body has yet to be found, her husband and his girlfriend were convicted of homicide. One of the items of evidence was a bloody tarpaulin (DNA showed the blood to be from the victim). Glitter particles were found on the tarp and were a match for those used by the girlfriend in arts and crafts work.

One last case is worth mentioning because it demonstrates the value of glitter as associative evidence in a totally different type of case [18]. Oftentimes in hit-and-run vehicle accidents or other types of automotive accident investigations, it is not too difficult to identify the vehicle(s) involved. The really difficult question is: Who was driving? This problem is even exacerbated today by the prevalence of cell phones. All a drunk driver has to do is abandon his/her vehicle at the accident scene, whip out a cell phone, and report to the 
police that his/her car was stolen! Or sometimes the driver will survive a crash but the passenger is killed, and when the police arrive the survivor denies being the driver. In a case in 2004 in Florida a mother and her daughter were killed when a pickup truck driven by an intoxicated woman slammed into the rear of their car. When police arrived no driver was present, but she was later found nearby hiding in the brush. She denied being the driver, but she was wearing cosmetic glitter and at the moment of impact some of it was transferred to the driver's side airbag!

\section{REFERENCES}

1. Aardahl K (2003). Evidential value of glitter particle trace evidence. Master's Thesis, National University, San Diego, CA, USA.

2. Jones EL Jr (2004). Trace evidence and bloodstain interpretation from the Sanchez/ Barroso case. Presented at the Fall Seminar of the California Association of Criminalists, Oct. 2004, Ventura, CA, USA.

3. Aardahl K, Kirkowski S, Blackledge RD (2005). A target glitter study. Science \& Justice 45: 7-12.

4. Deadman HA (1994). Fiber evidence and the Wayne Williams trial. FBI Law Enforcement Bulletin 53(3 \& 5), March (part 1): 12-20; May (part 2): 10-19.

5. Kirkowski S (2003). The forensic characterization of cosmetic glitter particles. Master's Thesis, National University, San Diego, CA, USA.

6. Smith J (2005). Personal communication, Criminalist III, Missouri State Highway Patrol Crime Lab, Jefferson City, MO, USA. See also http://caselaw.lp.findlaw. com/scripts/getcase.pl? court=mo\&vol=/supreme/062004/\&invol=40608_104.

7. Weber C (2004). Glitter as trace evidence. Master's Thesis, National University, San Diego, CA, USA.

8. Schubert GD (2004). Personal communication, Forensic Scientist, Illinois State Police, Southern Illinois Forensic Science Centre, Carbondale, IL, USA.

9. Kirk PL (1951). Density and Refractive Index: Their Application in Criminal Investigation, Charles C. Thomas, Springfield, IL, USA.

10. Smiths Detection (2005). Trace analysis of glitter particles, Application Brief AB-060. www.smithsdetection.com.

11. Larsen R (2006). Personal communication, Scientific Applications Manager, JASCO, Inc., Easton, MD, USA.

12. Gaenzle K (2006). Personal communication, Senior Metrology Engineer, Materials Analysis Laboratory, Naval Air Station, North Island, San Diego, CA, USA.

13. Grieve MC (1987). Glitter particles-an unusual source of trace evidence? Journal of the Forensic Science Society 27:405-412.

14. Alexanderv. State (8/21/92) ap-1242, appellate brief at: www.touchngo.com/ap/html/ ap-1242.htm.

15. Bradley MJ, Lowe PC, Ward DC (2003). Glitter: the analysis and significance of an atypical trace evidence examination. Poster presentation (Paper B24), at the Annual Meeting of the American Academy of Forensic Sciences, Chicago, IL, USA, Feb. 2003. See also www.lycolaw.org/cases/opinions/kramer010904a.PDF. 
16. Taylor CE (2004). Personal communication, Forensic Chemist, United States Army Criminal Investigation Laboratory, Forest Park, GA, USA.

17. Horner M (2000). Splitting hairs. www.markhorner.com/Hoss/splitting_hairs.html.

18. The Standard, Arrest made in the death of mother and daughter. Baker County, MacClenny, FL, USA, 28 May 2003. www.bcstandard.com/News/2003/0528/Front_ Page/001.html. 